
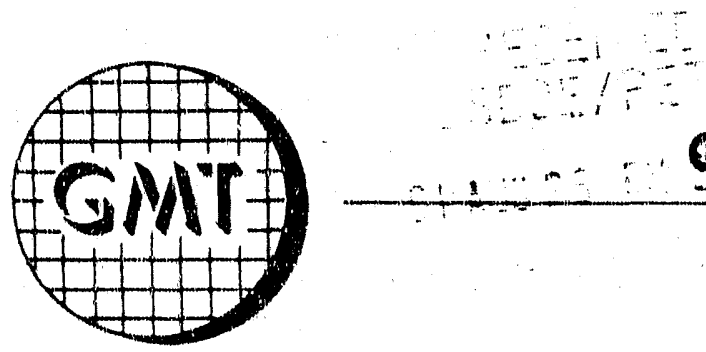

P O BOX132 EASTIAAIN STREET OCHELATA OKLAHOMA 7LOSI USA

PHONE IOIAI 535.2281 FAX $19181335256 \mathrm{~A}$

DOE/PC/89881--T5

D\$92 019002

Quarterly Report

April-June 1991

\title{
Microbial Recovery of Metals from Spent Coal Liquefaction Catalysts
}

Contract No.DEAC2289PC89881

\author{
Penny L. Sperl and George T. Sperl \\ Geo-Microbial Technologies, Inc. \\ P.o. Box 132, Ochelata, oK 74051
}

\section{DISCLAIMER}

This report was prepared as an account $n$ ? work sponsored by atl agensy of the United States Government. Neither the United Stisces Government nor any agency thereof, nor any of their employees, makes any warran's, express or implied, or assumes any legal liability or responsibility for the accuracy, completeness, or usefulness of any information, apparatus, product, or process disflosed, or represents that its uss, would not infringe privately owned rights. Reference berein to any specifis commercial product, process, or service by trade name, trademark, manufacturer, or otherwise does not necessarily constitute or imply its endorsement, recom. rilendation, of favoring by the United States Government or any agency thereof. The views and opinions of authors expresced berein do not necessarily state or reflect those of the United States Government or any agency thereof. 


\section{Abstract/Sumary}

\section{Introduction.}

This project was initiated on october 1,1989 , for the purpose of recovering metals from spent coal liquefaction catalysts. Two catalyst types are the subject of the contract. The first is a Ni-Mo catalyst supported on alumina (Shel1 324) as is used in a pilot scale coal liquefaction facility at Wilsonville, Alabama. This plant is run and operated by Solithern clean fuels. A large sample of spent catalyst from this facility has been obtained. The second material is an unsupported ammonium molybdate catalyst used in a pilot process by the Department of Energy at the Pittsburgh Energy Technology Center and has been subsequently dropped as a part of the work "This material was first obtained in late February 1990 but has not been pursued since the Mo content of this particular sample is too low for the current studies and no new catalyst has since been obtained ox produced by PETC. The object of the contract is to treat these spent catalysts with microorganisms, especially Thiobacillus ferrooxidars, but also other Thiobacillus sp. and possibly Sulfolobus, to leach and remove the metals ( $\mathrm{Ni}$ and Mo) from the spent catalysts into a form which can be readily recovered by conventional techniques.

\section{cultures.}

Cultures of $T$. ferrooxidans and $T$. denitrificans and related organisms were obtained from INEL, the American Type culture collection, and isolated from natural sources. The INEL medium for the cultivation of T. ferrooxidans was used with an initial $\mathrm{pH}$ of 2.0 ; this $\mathrm{pH}$ was later changed to 2.5 when better and more reproducible results were obtained at that pH. Thiobacillus denitrificans was cultured in the ATCC medium of choice (usually medium 450).

\section{Catalyst Treatment.}

The spent catalyst from wilsonville was treated initially by extensively washing the material with tetrahydrofuran in a soxhlet extractor and evaporating the THF fron the residual catalyst and the oil/THF-containing liquid. The dried catalyst was then crushed in a ball mill, producing fractions from 10 to smaller than 100 mesh. Minus 100 mesh material was initially used to assay metal release. This has since been replaced by 10 mesh or uncrushed material since microbial leaching appears to proceed just as well without crushing. 
Microbial Leaching studies.

During the seventh quarter of this contract, the use of $r$. ferrooxidans to leach catalyst was discontinued in favor of researching the accumulation of the leached metals and the other physical characteristics of the leached products. These studies form the jority of the body of this report.

\section{Strain Development.}

It is clear form our previous work and work in the last quarter that the development of a highly molybdate resistant strain of $T$. ferrooxidans will be very difficult, time consuming and possibly not successful enough to warrant the use of these organisms in the leaching of metals from Mo or $W$ containing catalysts. In addition, $T$. denitrificans and $T$. thiooxidans as well as sulfolobus sp. are not proficient leachers of the spent Shell 324 catalyst. It may still be possible to build a technology around $T$. ferrooxidans if the leached metals can be efficientiy and economically removed from the leachate as they are produced.

\section{Metal Recovery studies.}

During May and June we pursued the recovery of metals leached from the spent shell 324 catalyst. We first leached a about $100 \mathrm{~g}$ of the THF-washed spent catalyst and collected the supernatant solution containing both $\mathrm{Ni}$ and $\mathrm{Mr}$. This solution was filtered through a $0.22 \mu \mathrm{M}$ filter to removr, the bacteria and other small particulate matter. This solution was then passed over a chelex 100 column in the $\mathrm{Na}^{+}$form and the column washed with $10 \mathrm{ml}$ deionized water. The washings were combined with the unabsorbed material and analyzed for $\mathrm{Ni}$ and Mo. The column was then washed with 1 W HCl to elute the bound metals and the eluate analyzed. The results are shown in Table 1 . The initial unabsorbed liquids to which the washings were added were then treated to determine if the Mo was in an anionic state. This solution was passed through a Dowex $1 x-200$ anion exchange resin colum in the chloride form. After loading the column it was washed with deionized water and the washings added to the unabsorbed Iiquid materials. The colum was then eluted with $2 \mathrm{M}$ $\mathrm{KNO}_{3}$ and the eluate analyzed for $\mathrm{Mi}$ and Mo. The results are shown in Table 1.

It is quite clear from these data that the $\mathrm{Ni}$ is in a cationic form, i.e. most likely $\mathrm{Ni}^{++}$since typically only that form occurs in ordinary chemistry, the other oxidation states are very rare and the $N i$ in shell 324 is in predominantly in the +2 oxidation state. The data also unambiguously tell us that the Ho is in an anionic form. One would expect this because Mo in an aerobic aqueous solution usually is in some ionic form related to 
molybdate. However, since the form of the Mo in the catalyst is Mos a (i.e. the Mo is Mo+4, the oxidation state of the leached Mo is in doubt. clearly the leached Mo has formed some type of anion, and the penchant of ko to form polyanions and complexes, may leave its actual oxidation state open to question. To try to determine the actual oxidation state of Mo in these leachates we have sent a sample of dried leachate to Dr. G.P. Huffman, Director of the Consortiun for Fossil Fuel Liquefaction science at the University of Kentucky who will attempt to determine the valence of the Mo in the leachate. While this is important we should not lose sight of the fact that the leached Mo was readily recovered with the Dowex resin and the knowledge of its actual oxidation state may not be absolutely required for success of the project.

We have shown this month that we can recover both leached metals from the leachate using ion exchange technology.

Table 1

Ion Bxchange Properties of Leached Hetals

\begin{tabular}{lcc} 
Sample & Total ppm Ni & Total ppm Mo \\
\hline $\begin{array}{l}\text { Leachate } \\
\text { Haterial not absorbed to } \\
\text { Chelex + colum washings }\end{array}$ & 1280 & 2300 \\
$\begin{array}{l}\text { Chelex eluate } \\
\text { Material not absorbed to } \\
\text { Dowex }+ \text { column washings }\end{array}$ & 1120 & 2410 \\
Dowex eluate & 35 & $<10$ \\
\end{tabular}


Conclusions.

We have defined critical areas for furthej study. These arise out of the basic nature of both tre microorganisms and the nature of catalysts. Whereas other catalysts not employing Mo or $w$ would probably be readily leached by $T$. ferrooxidans, those which contain these two metals require special attention and highly tolerant strains of microorganisms to be realistically treated microbiologically. The alternative is to develop methods for the continuous removal of Mo as it is removed from the catalyst. We have preliminary data that show this to be technically feasible. The following are areas which need detailed study in the coming years.

1. To increase the molybdate tolerance of $T$. ferrooxidans. This j.ncrease could realistically also confer higher tolerance to w containing coal liquefaction catalysts. It is also clear that a major biochemical and genetic effort will be necessary to make this goal a success. This effort is beyond the scope of the current contract.

2. To further characterize the products of the leaching and identify the parameters necessary for the efficient recovery of both $\mathrm{Ni}$ and Mo. 

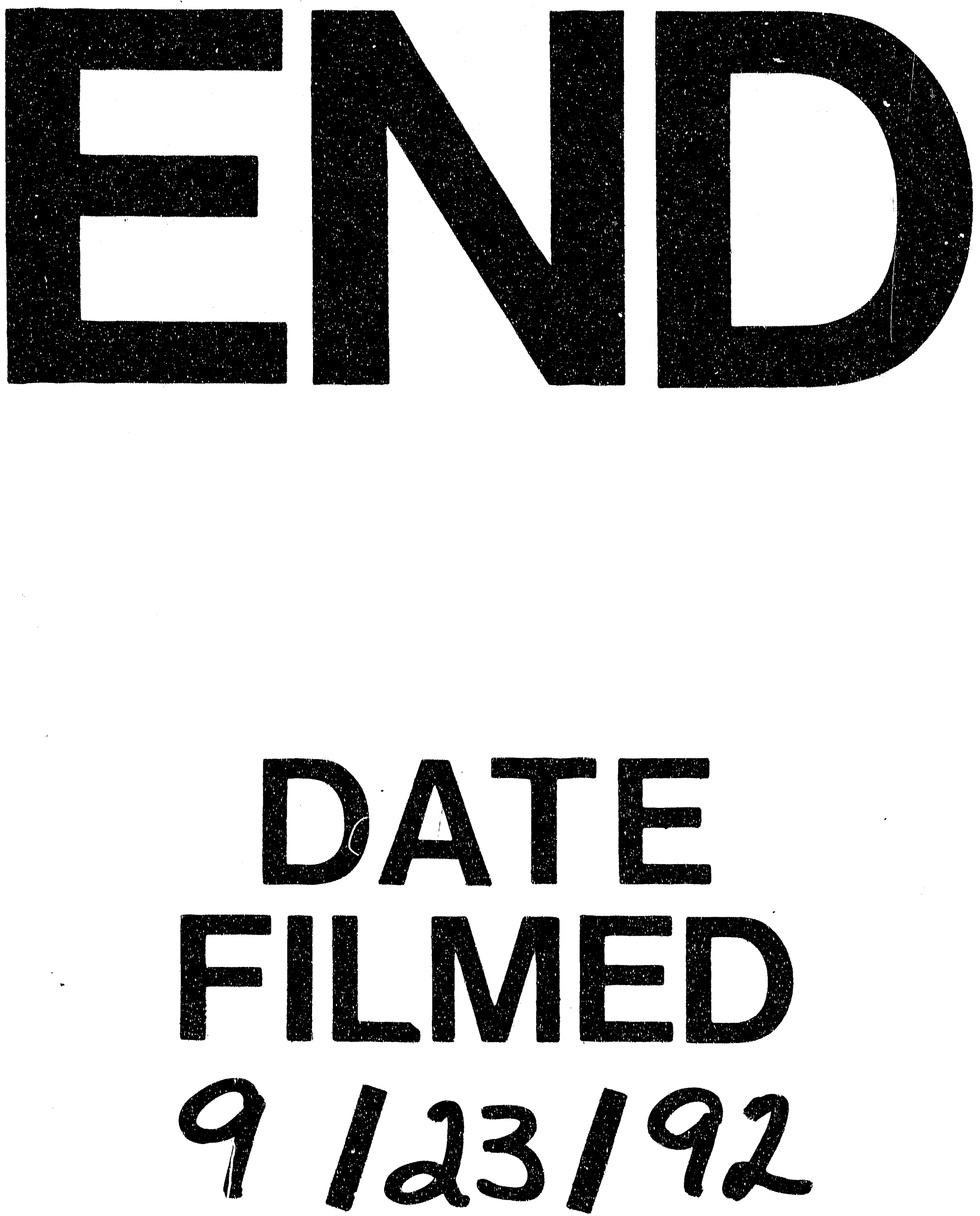
